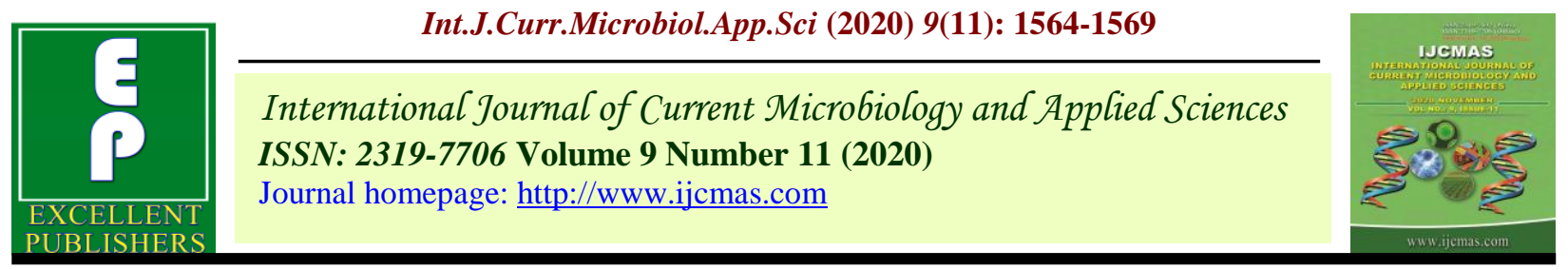

Original Research Article

https://doi.org/10.20546/ijcmas.2020.911.185

\title{
Evaluation of the Locally Available Substrates for the Cultivation of Ganoderma lucidum (W.Curt.:Fr.) Karst (Reishi Mushroom) in Prayagraj, U.P.
}

\author{
Zarzoliana Ralte*, Abhilasha A. Lal and Sobita Simon \\ Department of Plant Pathology, Sam Higginbottom University of Agriculture, \\ Technology and Sciences, Prayagraj, India \\ *Corresponding author
}

Keywords

Ganoderma

lucidum, Traditional medicine, Sawdust

Article Info

Accepted:

12 October 2020

Available Online:

10 November 2020

\section{A B S T R A C T}

Among many traditional medicines, Ganoderma lucidum has been used in Asian countries for over two millennia as a traditional medicine for maintaining vivacity and longevity. Ganoderma are indigenous to India but the cultivation is very less known to many mushroom farmers. An attempt was therefore made to cultivate with least input cost by utilizing locally available sawdust as base substrate supplemented with wheat bran and rice bran at different rates $(0 \%, 10 \%$, and $20 \%)$. Duration of growth cycle, yield and biological efficiency were recorded. Among the substrate mixture LMS + wheat bran (80:20) show a superior result with highest yield $(\mathrm{BE}=54.5 \%)$. However with respect to fructification, LMS + wheat bran (90:10) required the least duration (39.2 days) for maturation of the fruiting body. Yield and biological efficiency were enhanced by wheat bran and the latter rice bran is less suitable. Disease incidence is observed during the mycelial growth stages by fungal pathogens viz. Penicillium sp., Trichoderma sp. and Mycogone sp. in which management is assay in the first flush. With respect to yield, there is tremendous alteration compare to $1^{\text {st }}$ flush and $2^{\text {nd }}$ flush due to disease incidence.

\section{Introduction}

A mushroom of many names, Ganoderma lucidum (W.Curt.:Fr.) Karst is a member of fungal group Basidiomycetes which belongs to Polyporaceae (Ganodermaceae) of the order Aphyllophorales (Chang and Miles, 2004). Among many traditional medicines, it has been used in Asian countries for over two millennia as a traditional medicine for maintaining vivacity and longevity. It has been revered as "the mushroom of immortality" (Stamets, 2000). These mushroom species have important economic value, due to their medicinal properties and pathogenicity (Dai et al., 2007, 2009) and causes white rot of hard woods by decomposing lignin, cellulose and related polysaccharides (Hepting 1971, Adaskaveg et al., 1991). The bioactive constituents are reported to be responsible for antitumor, immunomodulatory, cardiovascular, respiratory, antihepatotoxic, and antinociceptive (acting against pain) effects (Chang and Miles 2004). Furthermore, in cosmetic products it shows inhibition activity 
against tyrosinase which is a key enzyme in the melanin formation (Chien et al., 2008). Hence, many facial mask cosmetics contain Ganoderma extracts which help in skin whitening (Hyde et al., 2010).

Mushroom cultivation is the only large scale biotechnological process that creatively utilizes lignocellulosics (Stamets, 2000). Currently, the most widely adopted cultivation method for commercial products are the wood logs method but there are certain limitations, as it required certain specific varieties of trees logs (Perumal, 2000).

Artificial cultivation has been achieved using substrates such as sawdusts (Chang and Buswell, 1999). The advantages of SSF (solid state fermentation) over other technique is that a concentrated product can be obtain from a cheap substrate, such as agricultural residue with little enrichment (Wagner et al., 2003).

The aim of the present study is to evaluate the locally available substrates (sawdust) with two supplements viz. wheat bran and rice bran at two different rates for the cultivation of Ganoderma lucidum with a segment of disease management.

\section{Materials and Methods}

\section{Settings and sampling}

The research experiment was carried out in the Mushroom Crop Room and Research Laboratory, Department of Plant Pathology, SHUATS, Prayagraj, Uttar Pradesh, India during the period from December, 2019 to March, 2020. The base substrate locally available sawdust is a mixture of different tree sawdust viz. Mango (Mangifera sp.), Wattle (Acacia sp.), Poplar (Populus sp.) and Sheesham (Dalbergia sissoo); brans of wheat (Triticum sp.) and rice (Oryza sp.) were collected from the local area.

\section{Mushroom cultures}

Pure culture is procured from ICARDirectorate of Mushroom Research, Solan, Himachal Pradesh, India. It was then sub culture in PDA (Potato Dextrose Agar) and incubated at $28^{\circ} \mathrm{C}$ until substantial mycelial growth was observed. This mycelium was then inoculated for spawn preparation on wheat grains (Triticum sp.).

\section{Experimental design}

In this experiment, the base substrate sawdust was supplemented at different rates i.e. $0 \%$ (control), $10 \%$ and $20 \%$ with wheat bran and rice bran respectively. Each treatment has five replicates, resulting in 25 experimental units. The effects of these experimental conditions were evaluated by their effect on complete spawn run period, time (days) needed for primordial formation, yield and biological efficiency (BE) of Ganoderma lucidum.

\section{Substrate preparation and inoculation}

Configuration of $\mathrm{pH}$, mixing of base substrate with supplement at different rates, obtaining ideal moisture content and substrate sterilization are included in substrate preparation. The locally mixed sawdust was stacked on a plastic sheet upon cemented floor and wetted thoroughly to obtain $60-70 \%$ moisture content approximately. Calcium sulphate (gypsum) and calcium carbonate (chalk powder) were added to achieve a $\mathrm{pH}$ of 5.5. Enrichment was done with supplements (wheat bran and rice bran) at different rate was mixed with the wetted sawdust. The tests substrate was then bagged in polypropylene bags each weighing $1 \mathrm{~kg}$ (350 g dry weight). Then the bags were labeled and closed with PVC (polyvinyl chloride) rings ( $3 \mathrm{~cm}$ diam.) and plugged with non- absorbent cotton to 
prevent contamination by airborne organisms while allowing air exchange. Bags were autoclaved at $121^{\circ} \mathrm{C}$ for $2 \mathrm{hr}$. After cooling the sterilized bags were inoculated at $3 \%$ spawn (w/w) i.e. $30 \mathrm{~g} / \mathrm{kg}$ of the wet substrate under aseptic condition (Laminar air flow).

\section{Cropping and harvesting}

Inoculated bags were incubated in dark room in a temperature maintained between $26 \pm 2^{\circ} \mathrm{C}$ by using electric heater. Humidity was maintained between $75-85 \%$ by spraying water thrice a day on gunny bags which is clip on the walls and the floor of the mushroom crop room.

The inoculated bags kept in cropping are to attain the five stages of mushroom growth: spawn run, primordial initiation, stalk formation, cap differentiation and maturation. The temperature and relative humidity were controlled at $27 \pm 2^{\circ} \mathrm{C}$ and $75-85 \%$ during the second stage with light exposure (10- $12 \mathrm{~h}$, provided by white fluorescent bulb of 1100 lux).The temperature and relative humidity were controlled at $27 \pm 2^{\circ} \mathrm{C}$ and $70-80 \%$ during the third stage (stalk formation) with light exposure.

The temperature and relative humidity were then controlled at $25^{\circ} \mathrm{C}$ and $75-85 \%$ during the fourth stage (cap formation) with light exposure and $27 \pm 2^{\circ} \mathrm{C}$ and $60-65 \%$ relative humidity during the last stage. All inoculated bags remained closed until the substrate in the bags was fully colonized. Completely colonized bag tops were cut at the level of the substrate to allow development of fruiting bodies.

Fruiting body was harvested when the pileus become fully brownish-red and is cover with spores. Total yield $(\mathrm{g} / \mathrm{kg})$ was obtained from two flushes. The BE percentage [(weight of fresh harvested mushroom/dry weight of the substrate) $\times 100$ ] was calculated.

\section{Disease management}

Disease has been identified by the detection method of symptoms on the substrate and microscopic observation. Fungal contamination occurs at the early stage and competitor molds viz. Penicillium sp., Trichoderma sp. And Mycogone sp. appear and tremendously affect the growth and yield of the first flush. Trichoderma sp. appeared late after pinhead formation by the incidence of mushroom flies. Penicillium sp. is observed early at spawn running stage and Mycogone sp. incidence is observed at the formation of pinhead which is deformed and the mature fruiting body grows abnormally showing an enlarged stipe and a small cap, while the surface of the fruiting body is covered with white fluffy mycelia, which turns brown and produces brown droplets. Trichoderma sp. is characterized by rapid onset and serious harm after the occurrence of the two fungal pathogens. In the mycelial growth stage, it causes the mycelia to lose culture substrates after the fungal invasion, while fungal mycelia also secrete toxins, inhibiting the mycelial growth, and then scrap the cloned bags. An approach is made to tackle the loss of bags by implementing fungicide (Carbendazim) at a very low rate at $0.2 \%$. It is sprayed inside the substrate bag where the competitors' myceliais seen with the help of a syringe at 7 days interval for 4 weeks. This management approach shows a quite remark on some treatments. Penicillium sp. and Mycogone sp. is no longer observed after the application of Carbendazim while Trichoderma sp. shows resistance against fungicide in a few treatments. Mushroom flies are monitor by keeping a yellow LED bulb (30w) wrap with white polythene sheets which is the coat with vegetable oils to attract the flies. Neem oil at $4 \%$ is sprayed on the substrate (lightly) and inside the room from the incidence of mushroom flies. 


\section{Statistical analysis}

The experimental design was based on Completely Randomized Designs (CRD) with 5 replications. The data were analyzed by using the analysis of variance (ANOVA) and significant differences between means were determined by the multiple comparison test of Turkey with $\alpha=0.05$.

\section{Results and Discussion}

Effect on combinations of sawdust and Supplements

The study was conducted to evaluate the best combination of media in stimulating the growth of Ganoderma lucidum so that productivity can be improved. Locally mixed sawdust and brans were mixed in different ratios (100, 90:10 and 80:20); inoculated in $3 \%$ spawn level. The findings reveal that supplemented bags at different concentrations have better results in terms of growth stages and yield than the one without supplementation. The variation in growth cycle among the treatments can be attributed to the change in decomposition rate of substrate component and disease incidence. Among two supplements (WB and RB) at variable concentration rates (10\% and 20\%), wheat bran (WB) show superiority than rice bran (RB) then comes without supplementation locally mixed sawdust (LMS) alone. In terms of fructification, LMS + WB 80:20 gave the highest yield (174.4 g) followed by LMS + WB 90:10 (171.7 g), LMS + RB 90:10 (163.5 g), LMS + RB 80:20 $(146.01 \mathrm{~g})$, as compared to control LMS $(121.5 \mathrm{~g})$ from a total of two flushes. In spawn running stage, LMS + WB 80:20 shows exquisite results than other combinations and the maximum day's requirement is recorded in LMS alone (without supplements). As of in pin head initiation LMS + WB 80:20 is superior over other combinations again and the maximum day's requirement is found in LMS alone. These results are in conformity with results in which it was reported that the minimum primordial formation was observed in substrate (sawdust) alone without supplement (Gurung et al., 2012). The lowest yield with LMS alone could be due to the carbon:nitrogen (C:N) imbalance in the substrate, which is in agreement with the observations of Stamets (2000). Furthermore, the efficiencies of brans are strongly agree with Erkel (2009). However, LMS + WB 90:10 require the least days for maturation, and overpassed the superiorly significant LMS + WB 80:20 (Fig. 1 and Table 1).

Table.1 Effect on combinations of sawdust and supplements doses on growth cycle and yield of Ganoderma lucidum

\begin{tabular}{|c|c|c|c|c|c|c|}
\hline $\begin{array}{c}\text { Substrate } \\
\text { combinations }\end{array}$ & $\begin{array}{c}\text { Supplement } \\
\text { Ratio (\%) }\end{array}$ & $\begin{array}{c}\text { Spawn } \\
\text { run } \\
\text { (Days) }\end{array}$ & $\begin{array}{c}\text { Primordia } \\
\text { initiation } \\
\text { (Days from } \\
\text { spawning) }\end{array}$ & $\begin{array}{c}\text { Maturation of } \\
\text { fruiting body } \\
\text { (Days from } \\
\text { spawning) }\end{array}$ & $\begin{array}{c}\text { Yield } \\
\text { (g/kg) }\end{array}$ & BE (\%) \\
\hline LMS & 0 & 24 & 31.4 & 44.4 & 121.5 & 35 \\
\hline LMS + WB & 10 & 19.4 & 26.4 & 39.4 & 171.7 & 53.5 \\
\hline LMS + WB & 20 & 17.4 & 21.8 & 39.2 & 174.4 & 54.5 \\
\hline LMS + RB & 10 & 20.4 & 26.2 & 40.8 & 163.5 & 51.9 \\
\hline LMS + RB & 20 & 21.8 & 30.4 & 42.2 & 145.5 & 46.8 \\
\hline
\end{tabular}


Fig.1 Effect on combinations of sawdust and supplements doses on growth cycle and yield of Ganoderma lucidum

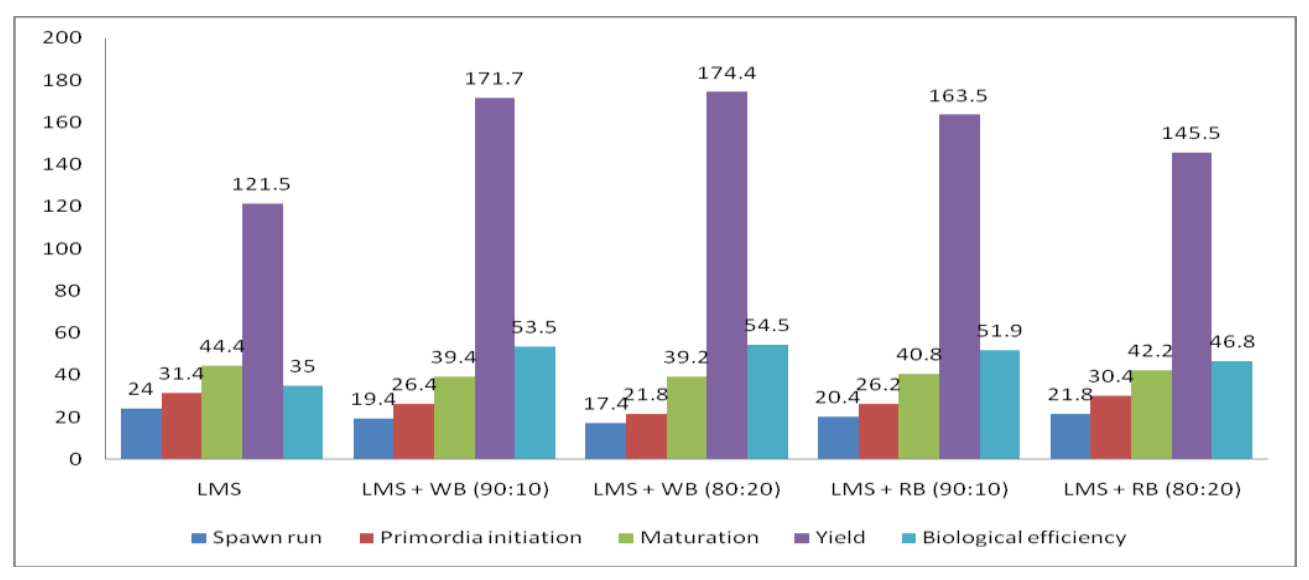

Plate.1 Comparison of $2^{\text {nd }}$ flush fruiting to $1^{\text {st }}$ flush fruiting after disease management
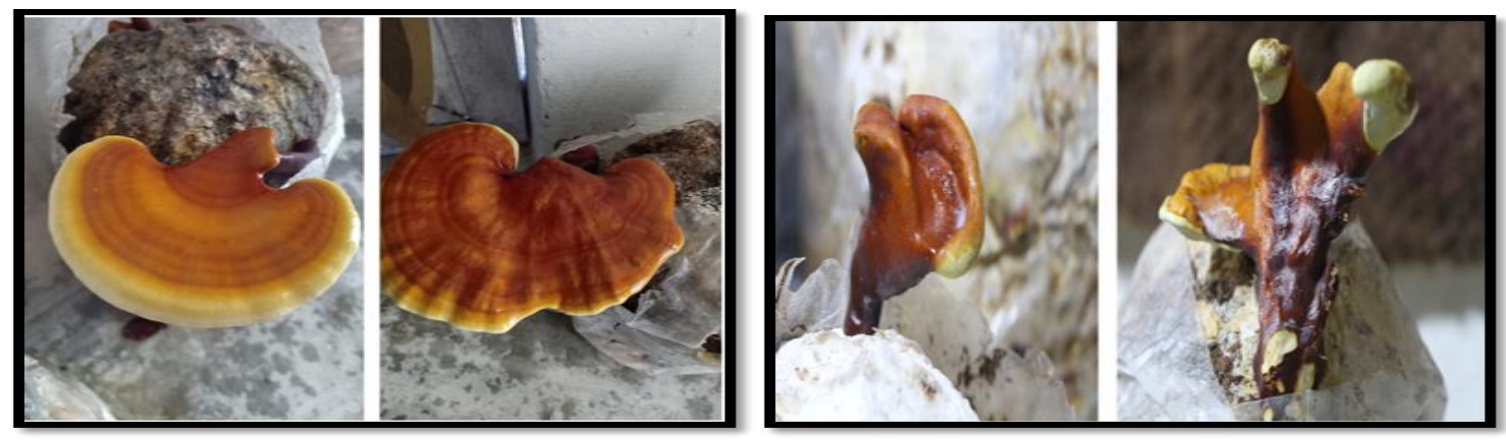

Maturity is affirmed when sporocarp produces spores and is visible on the surrounding of the fruiting body and conspicuously on the pileus. There is a tremendous alteration in the yield between $1^{\text {st }}$ flush and $2^{\text {nd }}$ due to appearance of contaminations which is being managed by utilizing management strategy and also believes that substrates with higher doses of supplementation are more susceptible to competitor's mold. Neem (Azadirachta sp.) oil act as both antagonists against flies and competitors mold and also believe that it increases the yield

The significant findings of the present study are the shorter growth cycle and higher yield and $\mathrm{BE}$ in Ganoderma lucidum can be obtained with Locally mixed sawdust supplemented with $20 \%$ wheat bran. Disease management should be also taken into further study as the management segment in this study has shown great potential. Cultivation of Ganoderma lucidum may be one of the most inexpensive and profitable agri-business especially in a region having vast hardwood area. Thus, these findings may be useful in many mycoremediation applications.

\section{References}

Adaskaveg, J.E., Blanchette, R.A. and Gilbertson, R.L. (1991). Decay of date palm wood by white-rot and brown-rot fungi. Canadian Journal of Botany, 69(3): 615-629.

Chang, S.T. and Buswell, J.A. (1999). 
Ganoderma lucidum (Curt.Fr.) P. Karst. (Aphyllophoromycetideae) - A mushrooming medicinal mushroom. International Journal of Medicinal Mushrooms, 1(2): 139-146.

Chang, S.T. and Miles, P.G. (2004). Mushrooms: Cultivation, Nutritional Value, Medicinal effect and Environmental Impact ( $2^{\text {nd }}$ edition) Boca Raton, CRC press.

Chien, C.C., Tsai, M.L., Chen, C.C., Chang, S.J and Tseng, C.H. (2008). Effects on tyrosinase activity by the extracts of Ganoderma lucidum and related mushrooms. Mycopathologia, 166(2): $117-120$

Dai, Y.C., Cui, B.K., Yuan, H.S. and Li, B.D. (2007). Pathogenic wood -decaying fungi in China. Forest Pathology, 37(2): 105-120.

Dai, Y.C., Yang, Z.L., Cui, B.K., Yu, C.J. and Zhou, L.W. (2009). Species diversity and utilization of medicinal mushrooms and fungi in China. International
Journal of Medicinal Mushrooms, 11(3): 287-302.

Erkel, E.I. (2009). The effect of different substrates mediums on yield of Ganoderma lucidum (fr.) Karst. Journal of Food Agriculture and Environment, 77(3): 841-844.

Gurung, O.K., Budathoki, U. and Parajuli, G. (2012). Effect of different substrates on the production of Ganoderma luicdum (Curt.:Fr.) Karst. Our Nature, 10: 191198.

Hepting, G.H. (1971). Diseases of forest and shade trees of the United States.US Department of Agriculture, Agriculture Handbook. 386: 1-658.

Wagner, R., Mitchell, D.A., Sassaki, G.L., M.A.L.D. Amazonas, Berovic, M. (2003). Current technique for the cultivation of Ganoderma lucidum for the production of biomass, ganoderic acid and polysaccharides. Food Technology and Biotechnology, 41(4): 371-382.

\section{How to cite this article:}

ZarzolianaRalte, Abhilasha A. Lal and Sobita Simon 2020. Evaluation of the Locally Available Substrates for the Cultivation of Ganoderma lucidum (W.Curt.:Fr.) Karst (Reishi Mushroom) in Prayagraj, U.P. Int.J.Curr.Microbiol.App.Sci. 9(11): 1564-1569.

doi: https://doi.org/10.20546/ijcmas.2020.911.185 